\title{
'Out with the old and in with the new' - a retrospective review of paediatric craniocervical junction fixation: indications, techniques and outcomes
}

\author{
Swan $\mathrm{AK}^{1}{ }^{1}$, Dunn $\mathrm{RN}^{2}$ \\ 1 MBChB(UCT), FC Orth(SA); Spine fellow, Department of Orthopaedic Surgery, University of Cape Town, Groote Schuur Hospital, Cape Town, South \\ Africa \\ 2 MBChB(UCT), MMed Orth(UCT), FC Orth(SA); HOD/Pieter Moll and Nuffield Chair of Orthopaedic Surgery, University of Cape Town, Groote Schuur \\ Hospital and Red Cross Children's Hospital, Cape Town, South Africa
}

Corresponding author: Prof RN Dunn, H49 Old Main Building Groote Schuur Hospital, Main Road, Observatory, Cape Town, South Africa, 7925; tel: +27 (0)21 404 5108; fax: +27 (0)21 447 2709; email: robert.dunn@uct.ac.za

\begin{abstract}
Background: The paediatric craniocervical junction has anatomical, physiological and biomechanical properties that make this region unique from that of the adult spine, vulnerable to injury, and contribute to the complexity of management. Traditionally, onlay fusion with external halo immobilisation has been used. Instrumented fusion offers intra-operative reduction and immediate stability.

Methods: A retrospective review of a single surgeon's prospectively maintained database was conducted for all cases of paediatric patients that had undergone a fusion involving the occipito-atlanto-axial region. Case notes were reviewed and a radiological analysis was done.

Results: Sixteen patients were managed with onlay fusion and external immobilisation, and 27 patients were managed with internal fixation using screw-rod constructs. The fusion rates were $80 \%$ and $90.5 \%$ respectively. Allograft bone grafting was found to be a significant risk factor for non-union.

Conclusion: The screws can be safely and predictably placed as confirmed on radiological follow-up with a high fusion rate and an acceptable complication rate. Uninstrumented onlay fusion with halo immobilisation remains an acceptable alternative. Allograft in the form of bone croutons or demineralised bone matrix is a significant risk factor for non-union, and posterior iliac crest graft should be used preferentially.
\end{abstract}

Level of evidence: Level 4

Keywords: paediatric, craniocervical junction, occipito-atlanto-axial, Harms

Citation: Swan AK, Dunn RN. 'Out with the old and in with the new' - a retrospective review of paediatric craniocervical junction fixation: indications, techniques and outcomes. SA Orthop J 2019;18(4):28-34. http://dx.doi.org/10.17159/2309-8309/2019/v18n4a3

Editor: Dr J Davis, Stellenbosch University, Cape Town, South Africa

Received: March $2019 \quad$ Accepted: May $2019 \quad$ Published: November 2019

Copyright: $\odot 2019$ Swan AK, Dunn RN. This is an open-access article distributed under the terms of the Creative Commons Attribution Licence, which permits unrestricted use, distribution and reproduction in any medium, provided the original author and source are credited.

Funding: No external funding was applied for nor obtained for this study.

Conflict of interest: Neither of the authors have any conflict of interest to declare related directly or indirectly to the research. 


\section{Introduction and aim}

Craniocervical junction (CCJ) instability is caused by traumatic and atraumatic aetiologies with underlying pathology of congenital, syndromic, autoimmune, inflammatory, infectious or neoplastic aetiologies. ${ }^{1,2} \mathrm{CCJ}$ instability may require surgical stabilisation from the pathology itself or for iatrogenic instability from decompressive surgery.

A successful CCJ fusion requires re-creation of a stable biomechanical environment and bony preparation for biological bony on-growth. Secondary goals include decompression and protection of neurological structures, restoration and maintenance of alignment, motion segment preservation, limitation of morbidity (including that of bone graft harvest), pain control, and the facilitation of nursing care. ${ }^{2-5}$ Consideration should be given to the benefits, risks and cost-effectiveness of the chosen method of stabilisation. ${ }^{3,5}$

A variety of techniques are available for stabilisation and fusion of the $\mathrm{CCJ}$ in paediatric patients: onlay fusion with external halo immobilisation, wiring techniques, and screw/screw-rod instrumented techniques with or without adjuvant wiring and external immobilisation.

In children younger than 8 years, the relatively large head, small occipital condyles, horizontally oriented atlanto-occipital and facet joints as well as capsular and ligamentous laxity make the CCJ the most significant transitional zone..$^{3,6-8}$ This unique anatomy of the $\mathrm{CCJ}$ in children complicates the interpretation of biomechanical studies that are largely done in adult cadaveric specimens. Anatomic size constraints, craniovertebral anomalies associated with congenital and syndromic conditions, immature ossification, as well as future growth potential, further complicate the decisionmaking process. ${ }^{3,9-11}$

Consequently, surgeons have until recently avoided instrumentation in the paediatric population. Having evolved from traditional onlay fusion with external halo immobilisation to internal fixation of the $\mathrm{CCJ}$ in paediatric patients with predominantly the Harms technique, we present our institutional experience and radiological outcomes.

\section{Methods}

A retrospective review of a single surgeon's prospectively maintained database was conducted for all cases of paediatric patients that had undergone a fusion involving the occipito-atlantoaxial region during the period 1 January 2002 to 31 August 2018.

Baseline demographic data, underlying pathology, indication for surgery, surgical technique, surgical parameters and intraoperative complications were assessed.

Pre- and post-operative radiology was used to assess implant placement and union. CT and MRI scanning were used at the discretion of the lead surgeon on a per case basis. Fusion was assessed on antero-posterior and lateral radiographs as either cross trabeculation of fusion mass (Figure 1); or the absence of peri-screw lucency, absence of instrumentation failure and stability on flexion/extension views when adequate visualisation of the fusion mass was not possible. ${ }^{12}$ Typically, concealment of the fusion mass is due to the instrumentation (Figure 2).

Case notes were reviewed for any complications and progress during the follow-up period.

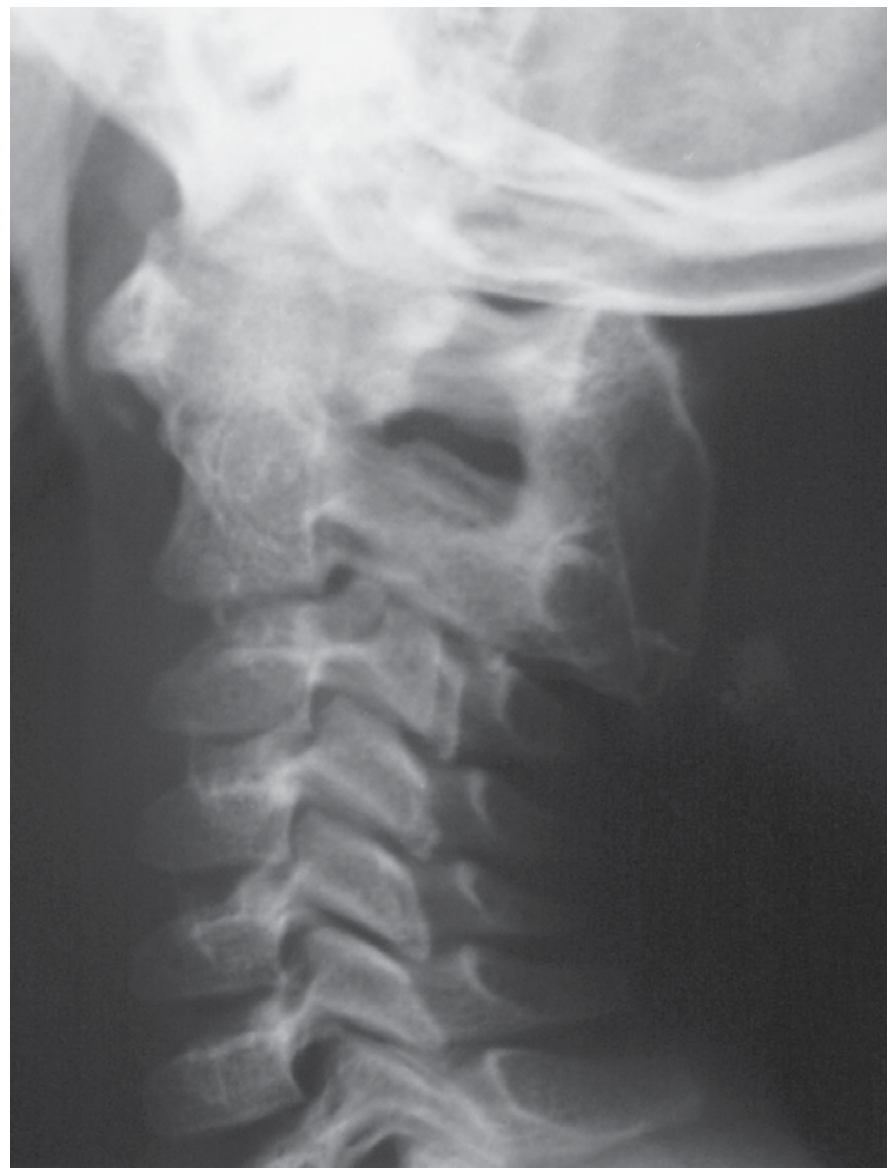

Figure 1. Lateral cervical spine $\mathrm{X}$-ray demonstrating $\mathrm{C} 1-\mathrm{C} 2$ fusion achieved with an uninstrumented fusion technique with halo external immobilisation

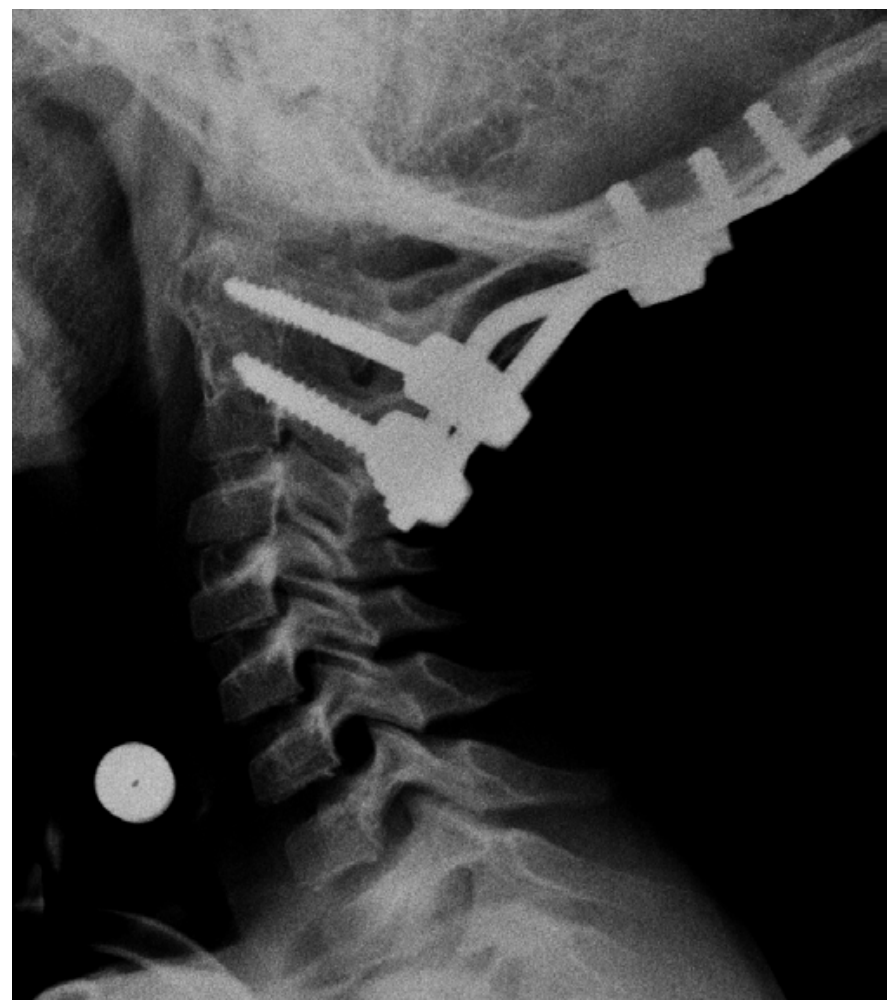

Figure 2. Lateral cervical spine X-ray demonstrating partial concealment of the fusion mass due to screw-rod instrumentation. This was accepted as fused as there is no implant loosening or failure and no motion demonstrated on flexion-extension views. 


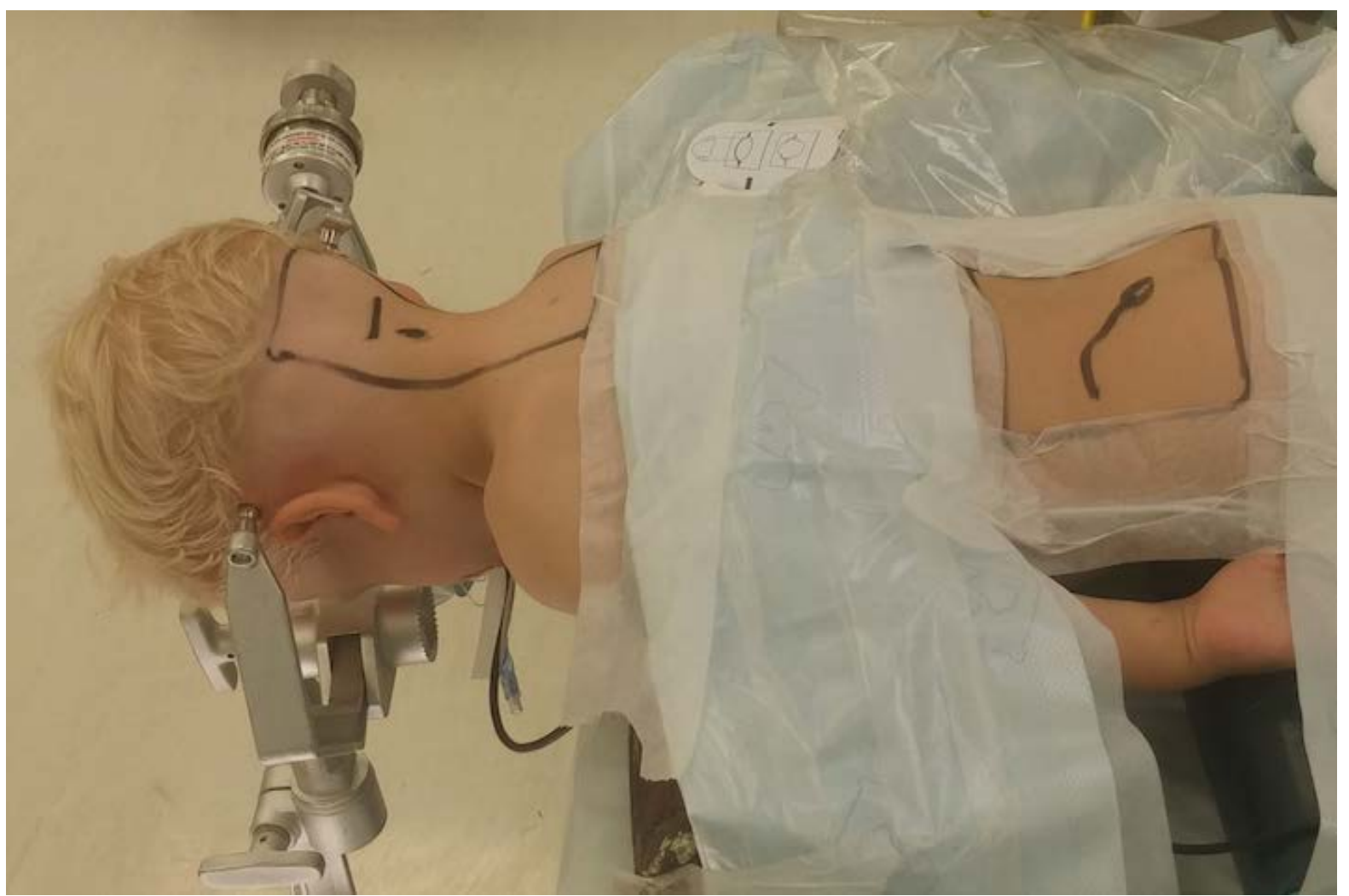

Figure 3. The patient is positioned prone on a Montreal mattress and positioned in the 'military chin-tuck position'. The patient is draped for posterior iliac crest autograft harvest.

\section{Surgical technique}

\section{Halo external immobilisation}

The patient is positioned supine. Between four and eight pins are placed with between 40 and 60 pounds per square inch and attached to the halo ring. Reduction of the deformity is confirmed on lateral imaging and the halo is secured to the jacket.

\section{Screw-rod}

The patient is positioned prone on either a Relton Hall or Montreal mattress and the skull is held with a Mayfield clamp (Figure 3). The patient's neck is positioned in the 'military chin-tuck position' and slight flexion to improve access, and attempted reduction of the $\mathrm{C} 0-\mathrm{C} 1-\mathrm{C} 2$ joints is done when possible.

A midline skin incision is used in all cases here, with subperiosteal exposure of the intended fusion levels. A Watson-Cheyne dissector is placed into the $\mathrm{C} 1-\mathrm{C} 2$ joint to retract the $\mathrm{C} 2$ root inferiorly and gain access to the $\mathrm{C} 1$ lateral mass entry point. $\mathrm{A}$ burr is used to create a cortical breach in the lateral mass as it joins the $\mathrm{C} 1 \mathrm{arch}$. $\mathrm{A}$ $2.7 \mathrm{~mm}$ drill bit is used in oscillating mode and drilled with $10-15^{\circ}$ convergence and parallel to the arch under lateral imaging.

During C2 pedicle screw insertion, the C2-C3 facet joint is identified but not exposed. The starting point is created using a burr in the infero-lateral quadrant of the $\mathrm{C} 2$ lateral mass to optimise screw length. The medial border of the $\mathrm{C} 2$ pedicle is identified by palpation using a blunt hook or Watson-Cheyne and is drilled using oscillating mode with approximately $20^{\circ}$ convergence and parallel to the $\mathrm{C} 2$ pedicle as visualised on lateral imaging.

All drill holes are probed to exclude cortical breech and to confirm screw length prior to screw placement. A standard cervical set with $3.5 \mathrm{~mm}$ screws is used for all cases reported here.
The intended fusion levels are decorticated and, in most cases, cortico-cancellous strips harvested from the posterior iliac crest are packed underneath the screw-rod construct and occasionally secured with an absorbable suture when deemed necessary.

When allograft is used, it is in the form of SA bone croutons or demineralised bone matrix (DBM).

A soft collar is used post-operatively for a period of six weeks.

\section{Statistical analysis}

Analysis was performed using the $\mathrm{R}$ language and environment for statistical computing (version 3.5.2) (R Foundation for Statistical Computing, Vienna, Austria).

\section{Results}

Forty-three consecutive paediatric patients underwent a fusion involving the occipito-atlanto-axial region during the study period.

Sixteen consecutive patients with a mean age of 7.5 years (range 3.8-13.8 years) had uninstrumented onlay fusion with halo immobilisation. Pre-operative CT scan was done for two patients and pre-operative MRI for one patient. Fifteen of these patients had adequate radiological follow-up for analysis.

Twenty-seven consecutive patients with a mean age of 9.8 years (range 2.2-16.7 years) had instrumented internal fixation. Preoperative CT scan was done for 16 patients and pre-operative MRI for 15 patients. Twenty-one of these patients had adequate radiological follow-up for analysis.

The most common underlying diagnoses were trauma and os odontoideum. Indications for surgery included non-traumatic instability (17 patients), traumatic instability (13 patients) and instability with myelopathy (eight patients). A breakdown of the underlying diagnosis and indication for surgery are given in Tables I and II. 
The screw configuration for the 27 instrumented fusion group included 13 skull plates, 16 bilateral $\mathrm{C} 1$ lateral mass screws, 23 bilateral C2 pedicle screws, three bilateral C2 translaminar screws and one patient with unilateral $\mathrm{C} 2$ and $\mathrm{C} 3$ translaminar screws.

The median operative time for uninstrumented fusion was 45 minutes (interquartile range $44-61 \mathrm{~min}$ ), and 100 minutes (interquartile range 80-120 min) for instrumented fusion. Operative time was found to be significantly different between the two groups $(p<0.01)$. The median blood loss for uninstrumented fusion was $100 \mathrm{ml}$ (interquartile range $50-100 \mathrm{ml}$ ), and $150 \mathrm{ml}$ (interquartile range 100-250 ml) for instrumented fusion. Blood loss was found to be significantly different between the two groups $(p=0.01)$.

Fifteen of the 16 patients managed with uninstrumented onlay fusion were followed up for a median period of 19.5 months (interquartile range 11-27 months) and had adequate radiological follow-up for analysis. The union rate for this group was $80 \%$ at a median period of two months (interquartile range 2-8 months), with two patients achieving a stable pseudarthrosis and one patient who represented with a non-union and a myelopathy following a subtle injury six years later. A successful union was achieved in this patient with instrumented fusion and autograft.

Twenty-one of the 27 patients managed with instrumented fusion were followed up for a median period of 22 months (interquartile range 11-37 months), and had adequate radiological follow-up for analysis. Unfortunately, as many of these patients were treated as out-patients and often followed up at institutions near their homes, X-rays were not available as frequently. A union rate of $90.5 \%$ was observed for this group in a mean period of 4 months (interquartile range 3-12 months). One patient achieved a stable pseudarthrosis and another managed initially with allograft had hardware failure but was successfully revised and achieved union with autograft.

Autograft harvested from the posterior iliac crest was used for all but two patients in the halo group and three patients in the instrumented group, where allograft in the form of bone croutons or DBM was used.

Table I. Underlying diagnosis

\begin{tabular}{|l|c|}
\hline \multicolumn{1}{|c|}{ Diagnosis } & Number \\
\hline Trauma & 13 \\
\hline Os odontoideum & 13 \\
\hline Atlantoaxial rotatory subluxation & 4 \\
\hline Morquio syndrome & 4 \\
\hline Basilar invagination & 3 \\
\hline Trisomy 21 & 2 \\
\hline Conradi-Hunermann syndrome & 2 \\
\hline Tuberculosis & 2 \\
\hline
\end{tabular}

Table II. Indications for surgery

$$
\text { Indication for surgery }
$$

Instability

Instability: non-trauma

Instability: trauma

nstability with myelopathy

Myelopathy

Instability with radiculopathy
When comparing graft type across both groups, allograft use was found to be a significant risk factor for non-union $(p=0.01)$. In isolation, allograft was found to be a significant risk factor for non-union in the uninstrumented group $(p=0.03)$, but not for the instrumented group $(p=0.27)$.

Including patients who failed to achieve bony union, there was a $25 \%$ complication rate for the halo group. One patient developed pin-site infection which was successfully treated with antibiotics, and another with a non-union who presented myelopathic following a subtle injury at six years post attempted fusion.

The instrumented fusion group had a complication rate of $21 \%$. One patient developed a wound infection requiring operative washout, two durotomies during dissection were repaired without incident, and one presumed vertebral artery (VA) injury during dissection was controlled and resulted in no adverse outcome.

No malposition of screws was noted on any of the post-operative radiological imaging.

\section{Discussion}

Wiring techniques are biomechanically inferior to screw and screwrod constructs and show a significant decrease in stability when physiological loading is applied. ${ }^{13-15}$ This necessitates supplemental external immobilisation and frequently the incorporation of subaxial levels to improve stability. ${ }^{1,16,17}$ In patients younger than 2 years, the soft cartilaginous bone may not withstand the tensile load from wiring. ${ }^{6}$ Congenital, dysplastic or absent posterior elements, or in cases when posterior decompression is required, limitation of fixation points, may preclude the use of wiring techniques or require the inclusion of additional subaxial levels. ${ }^{18}$ Complications of wiring techniques include compression or injury to dura and neurological structures during sublaminar passage of wires especially with inadequate reduction, wire cut-out or loosening, and suboptimal non-union rates as high as $30 \% .1,5,13,16,17,19$

A case control study of 27 adults comparing C1-C2 transarticular screw fixation (TASF) with collar and posterior wiring with halo, showed a significant 21 times improvement in union rate with TASF $^{20}$ TASF is frequently augmented with posterior wiring techniques compounding the risks of the procedure.

Halo immobilisation is cumbersome, poorly suited to polytrauma patients who require stability to aid nursing care, and not without complications. Halo management can be labour-intensive, often requiring inpatient care for pin-site hygiene and regular tightening. Biomechanically in adults, halos have been shown to have less ability to reduce sagittal plane motion at the atlantoaxial complex (by $71 \%$ ) than a Philadelphia collar. ${ }^{21}$ Pin-tract loosening and infection, dural puncture and neurological complications are all associated with halo use, and the overall complication rate is as high as $53-68 \% .^{16,22-25}$ We achieved an $80 \%$ union rate and had a $25 \%$ complication rate using this method.

Screw and screw-rod constructs have gained popularity for the improved stability, fusion rates and shorter duration to fusion. ${ }^{1,5,14,18,26} \mathrm{~A}$ variety of fixation points are available: $\mathrm{C} 1-\mathrm{C} 2$ transarticular screw fixation; C1 lateral mass or pedicle screw; C2 pedicle, pars or translaminar screws; and subaxial translaminar or lateral mass screws. ${ }^{27}$ Recently, $\mathrm{C} 1$ pedicle screws have been advocated to reduce venous plexus bleeding, C2 nerve root injury, and reliance on fluoroscopy during insertion. ${ }^{11}$ 
When interpreting biomechanical studies comparing the various fusion techniques, consideration should be given to the fact that the primary motion at the occipitocervical (OC) joint is in the sagittal plane, while primary motion at the atlantoaxial joint is axial rotation and anterior/posterior translation in pathological states. ${ }^{28}$ Results of various adult cadaveric biomechanical studies vary slightly when comparing TASF and the Harms technique, with some showing no difference ${ }^{15}$ and others showing a trend to improved stability with either the Harms technique ${ }^{1,29,30}$ or TASF. ${ }^{31}$ Both the Harms technique and TASF have improved stability over translaminar screw techniques. . $^{30,31}$

A tomographic analysis of children aged 2-6 years concluded that midline occipital plates could be used in $100 \%$ of cases; standard $3.5 \mathrm{~mm}$ screws could be used in $100 \%$ of $\mathrm{C} 1$ lateral mass screws, $74 \%$ of $\mathrm{C} 2$ pedicle screws, and $98 \%$ of bilateral C2 translaminar screws, yet only $4 \%$ were deemed suitable for TASF $^{32}$ Another study done in 94 paediatric patients 6 years and older found that $3.2 \%$ were unsuitable for TASF bilaterally, $18 \%$ unsuitable for unilateral TASF and $5.3 \%$ feasible but risky. It was suggested that careful scrutiny of CT scans be done for the course of the VA and pre-operative planning. ${ }^{33}$ Analysis of 69 patients younger than 16 years found only $30.4 \%$ of $C 2$ suitable to accept bilateral translaminar screws. ${ }^{34}$ It has been suggested that screws with a larger diameter than the cortex may be accommodated by the viscoelastic properties of bone in children. ${ }^{11}$

C1-C2 TASF popularised by Margel for the longer screw length and purchase of at least three cortical surfaces may be precluded by anatomic variability in $20 \%$ of cases..$^{1,27}$ This technique requires reduction of the $\mathrm{C} 1-\mathrm{C} 2$ facet joint prior to screw placement, and as the variable location of the transverse foramen and the medial trajectory of the screw increases the risk of VA injury, pre-operative CT planning is strongly advocated. ${ }^{1,3,4,9,16,26,35-38}$ Other difficulties with TASF are the acute angle of screw placement in cases of kyphosis, obesity or barrel chest; and the additional risk during supplemental wire fixation, which is frequently done. . $^{4,10,26,29,35,36,38,39}$

The major benefit of screw-rod constructs are the versatility of fixation options and constructs. The construct can be used as a means of intra-operative reduction through compression, distraction or cantilever techniques; it is better able to conform to, and contour the individual anatomy; and can be used in congenital or decompressive cases with hypoplasia or absence of posterior elements. . $^{18,26,37,39,40}$ The morbidity of transoral decompression may be avoided by the indirect decompression gained by reducing the deformity using screw-rod techniques, and the direct posterior decompression of lamina or foramen magnum that this technique allows. ${ }^{41-43}$ The trajectory of the $\mathrm{C} 1$ lateral mass screw may make vertebral artery injury less likely than that of TASF, reducing the dependence on pre-operative CT scanning. 1,4,29

A retrospective review of 191 adults managed with TASF showed that $92 \%$ of sides were suitable for TASF with a $1.4 \%$ chance of VA injury per screw placed. The overall complication rate was $16.7 \%{ }^{44}$ A retrospective review by the lead author (RD) of 19 adult patients who successfully underwent TASF had a $21 \%$ complication rate including one VA injury without consequence. Union was achieved in all patients. ${ }^{45}$ Several retrospective reviews of TASF in paediatric patients, most augmented with posterior wiring and autograft, had a union rate of $94-100 \%$ at a mean period of 4-7 months. The complication rate for the procedure varied from $11.8-25 \%$ with the risk of VA injury between $1.6-2.9 \%$ per screw placed. All had preoperative CT planning and $89-95 \%$ of sides were deemed suitable for transarticular screw placement. $35,38,46-48$

A meta-analysis of mostly level 3 evidence of screw-rod fixation in patients over 18 years included 1073 patients across 24 studies. The overall union rate was $97.5 \%$ and complications directly attributable to surgery were $0.2 \%$. The overall VA injury rate was $0.6 \%$ with $0.4 \%$ occurring during dissection, and $0.1 \%$ for $\mathrm{C} 1$ and
C2 screw placement. Mention is made of exercising caution during dissection over the lateral aspect of the posterior arch of $\mathrm{C} 1$. Screw malposition requiring revision for $\mathrm{C} 1$ lateral mass (LM) was $0.3 \%$ and $0.1 \%$ for $\mathrm{C} 2$ pars/pedicle screws. The overall minor complication rate was $9.1 \%$ with $7.7 \%$ related to $\mathrm{C} 2$ root morbidity. ${ }^{49}$ Less data is available for union rate, period to union and complication rate for screw-rod constructs in paediatric patients than for TASF.

Retrospective reviews of screw-rod fixation with mainly $\mathrm{C} 1$ lateral mass and C2 pedicle or pars screws indicate a 93-100\% union rate with a mean time to fusion of between 4.1 and 7.3 months. The minor complication rate varies between 7 and 33\% if smaller case series are included. $4,9,11,40,50,51$ Only one VA injury was seen in a small retrospective review of four cases. ${ }^{9}$ We achieved an acceptable union rate of $90.5 \%$ with a $21 \%$ complication rate $(7.4 \%$ re-operation rate). Mixed adult and paediatric retrospective reviews suggest a low risk of VA injury of up to $1.3 \%$ per side. ${ }^{41,52,53}$ Screwrod fixation using $\mathrm{C} 2$ translaminar screws has also been used with a low complication and high union rate. ${ }^{54-56}$

Retrospective reviews comparing adult and paediatric patients undergoing fusion with either Harms or TASF showed no difference in union rate, operative time or risk of VA injury. 8,39 Blood loss has been shown to be significantly higher for the Harms technique. ${ }^{39}$ In paediatric patients, hardware failure is associated with skeletal dysplasia or congenital spine anomalies and not the fixation method. Deep wound infection is a risk factor for requiring surgical revision of instrumentation or graft. ${ }^{37}$ Dunn et al. in a retrospective series of 42 adults undergoing TASF or Harms found no difference in surgical time; however, blood loss and cost of implants was higher for Harms technique. The VA injury rate was $14.8 \%$ for TASF and $6.7 \%$ for Harms. The higher overall VA injury rate may reflect the lack of CT scan availability at the time of the study. ${ }^{57}$ In the paediatric population undergoing $\mathrm{C} 1-\mathrm{C} 2$ screw-rod fixation, the mean operative time varies from 109 to $138 \mathrm{~min}$ and the mean blood loss varies from 68 to $155 \mathrm{ml}$, with lower operative times and blood loss generally seen when allograft is used.11,40,50 This is comparative with our experience.

While it is widely accepted that autograft is the gold standard for achieving fusion, harvesting from the iliac crest is associated with increased blood loss, operative time and donor site morbidity. ${ }^{50,58,59}$ Open posterior cervical surgery creates a large potential 'dead space', allowing the graft to drift back when the patient is positioned supine post-operatively. It is suspected that this is a reason for the reduced fusion rate seen with the use of allograft croutons in this series. Structural graft that is secured to the fusion site is therefore favoured. There has been success in paediatric patients with the use of structural allograft placed under compression at the C1-C2 fusion site with fusion rates of $97-100 \%{ }^{50,59}$ However, time to fusion may be significantly less than with autograft use..$^{50}$

The retrospective nature of the study is an inherent limitation. Other limitations include concealment of the fusion mass on the X-ray by the screw-rod constructs which can make interpretation of union difficult; and patient fallout due local follow-up, resulting in infrequent radiological follow-up, and thus determining the period to union is inaccurate, particularly in the instrumented fusion group.

\section{Conclusion}

Instrumentation of the paediatric cervical spine is both possible and safe, despite the anatomical size constraints. Instrumented fusion of the paediatric craniocervical junction using screw-rod constructs offers versatility, is useful as an intra-operative reduction aid, and allows immediate stabilisation following decompressive procedures.

The immediate stability creates a biomechanical environment with a high fusion rate and an acceptable complication rate. 
Uninstrumented onlay fusion with halo immobilisation remains an acceptable alternative despite the challenges of intensive outpatient care.

Allograft in the form of bone croutons or DBM is a significant risk factor for non-union and should not be used.

\section{Ethics statement}

The author/s declare that this submission is in accordance with the principles laid down by the Responsible Research Publication Position Statements as developed at the 2nd World Conference on Research Integrity in Singapore, 2010.

Prior to commencement of the study ethical approval was obtained from the University of Cape Town Human Research Ethics Committee (HREC 051/2019).

\section{Declaration}

The authors declare authorship of this article and that they have followed sound scientific research practice. This research is original and does not transgress plagiarism policies.

\section{Author contributions}

$\mathrm{RD}$ was responsible for the conceptualisation, and contributed to the design, data collection, manuscript preparation and final write-up.

AS was responsible for the design, data collection, manuscript preparation and final write-up.

\section{ORCID}

AK Swan (ID https://orcid.org/0000-0003-2940-5928

RN Dunn (i) https://orcid.org/0000-0002-3689-0346

\section{References}

1. Inamasu J, Kim DH, Klugh A. Posterior instrumentation surgery for craniocervical junction instabilities: an update. Neurol Med Chir (Tokyo). 2005;45(9):439-47.

2. Vaccaro ARBEM. Spine Surgery. 2nd ed: Elsevier Saunders; 2012.

3. Douglas L. Brockmeyer. Lateral mass screw fixation of C-1. Journal of Neurosurgery: Pediatrics. 2007;107(2):173-74.

4. Heuer GG, Hardesty DA, Bhowmick DA, Bailey R, Magge SN Storm PB. Treatment of pediatric atlantoaxial instability with traditional and modified Goel-Harms fusion constructs. European Spine Journal. 2009;18(6):884-92.

5. Winegar CD, Lawrence JP, Friel BC, Fernandez C, Hong J, Maltenfort $\mathrm{M}$, et al. A systematic review of occipital cervical fusion: techniques and outcomes. J Neurosurg Spine. 2010;13(1):5-16.

6. Benzel EC, Zhang DH, lannotti C, Refai D, Ruggieri P, Krishnaney A. Occipitocervical fusion in an infant with atlantooccipita dislocation. World Neurosurgery. 2012;78(6):715. e17-e24.

7. Junewick JJ. Pediatric craniocervical junction injuries. American Journal of Roentgenology. 2011;196(5):1003-10.

8. Hankinson TC, Avellino AM, Harter D, Jea A, Lew S, Pincus D, et al. Equivalence of fusion rates after rigid internal fixation of the occiput to C-2 with or without C-1 instrumentation. Journal of Neurosurgery: Pediatrics. 2010;5(4):380-84.

9. Jea A, Taylor MD, Dirks PB, Kulkarni AV, Rutka JT, Drake JM. Incorporation of $\mathrm{C}-1$ lateral mass screws in occipitocervical and atlantoaxial fusions for children 8 years of age or younger Technical note. J Neurosurg. 2007;107(2 Suppl):178-83.

10. Gluf WM, Brockmeyer DL. Atlantoaxial transarticular screw fixation: a review of surgical indications, fusion rate, complications, and lessons learned in 67 pediatric patients. Journal of Neurosurgery: Spine. 2005;2(2):164-69.

11. Zhang Y-H, Shao J, Chou D, Wu J-F, Song J, Zhang J. C1-C2 Pedicle screw fixation for atlantoaxial dislocation in pediatric patients younger than 5 years: a case series of 15 patients. World Neurosurgery. 2017;108:498-505.

12. Bick S, Dunn R. Occipito-cervical fusion: review of surgical indications, techniques and clinical outcomes. SA Orthopaedic Journal. 2010;9(4):26-32.

13. Dickman CA, Crawford NR, Paramore CG. Biomechanical characteristics of C1-2 cable fixations. Journal of Neurosurgery. 1996;85(2):316-22.

14. Hurlbert RJ, Crawford NR, Choi WG, Dickman CA. A biomechanical evaluation of occipitocervical instrumentation screw compared with wire fixation. J Neurosurg. 1999;90(1 Suppl):84-90.

15. Melcher RP, Puttlitz CM, Kleinstueck FS, Lotz JC, Harms J, Bradford DS. Biomechanical testing of posterior atlantoaxial fixation techniques. Spine. 2002;27(22):2435-40.

16. Kukreja S, Ambekar S, Sin AH, Nanda A. Occipitocervical fusion surgery: review of operative techniques and results. J Neurol Surg B Skull Base. 2015;76(5):331-39.

17. Mazur MD, Ravindra VM, Brockmeyer DL. Unilateral fixation for treatment of occipitocervical instability in children with congenital vertebral anomalies of the craniocervical junction. Neurosurgical focus. 2015;38(4):E9.

18. Goel A, Laheri V. Plate and screw fixation for atlanto-axial subluxation. Acta Neurochir (Wien). 1994;129(1-2):47-53.

19. Lundy DW, Murray HH. Neurological deterioration after posterior wiring of the cervical spine. The Journal of Bone and Joint Surgery British volume. 1997;79(6):948-51

20. Taggard DA, Kraut MA, Clark CR, Traynelis VC. Case-control study comparing the efficacy of surgical techniques for $\mathrm{C} 1-\mathrm{C} 2$ arthrodesis. Clinical Spine Surgery. 2004;17(3):189-94.

21. Koller $\mathrm{H}$, Zenner J, Hitzl W, Ferraris $\mathrm{L}$, Resch $\mathrm{H}$, Tauber $\mathrm{M}$, et al. In vivo analysis of atlantoaxial motion in individuals immobilized with the halo thoracic vest or Philadelphia collar. Spine. 2009;34(7):670-79.

22. Lowry DW, Pollack IF, Clyde B, Albright AL, Adelson PD. Upper cervical spine fusion in the pediatric population. J Neurosurg. 1997;87(5):671-76.

23. Schultz Jr KD, Petronio J, Haid RW, Rodts GE, Erwood SC, Alexander J, et al. Pediatric occipitocervical arthrodesis. Pediatric Neurosurgery. 2000;33(4):169-81.

24. Dormans JP, Criscitiello AA, Drummond DS, Davidson RS. Complications in children managed with immobilization in a halo vest. JBJS. 1995;77(9):1370-73.

25. Limpaphayom N, Skaggs DL, McComb G, Krieger M, Tolo VT. Complications of halo use in children. Spine. 2009;34(8):779-84.

26. Nockels RP, Shaffrey $\mathrm{Cl}$, Kanter AS, Azeem S, York JE. Occipitocervical fusion with rigid internal fixation: long-term follow-up data in 69 patients. J Neurosurg Spine. 2007;7(2):117-23.

27. Anderson RC, Ragel BT, Mocco J, Bohman LE, Brockmeyer DL. Selection of a rigid internal fixation construct for stabilization at the craniovertebral junction in pediatric patients. J Neurosurg. 2007;107(1 Suppl):36-42.

28. Wolfla CE. Clinical and biomechanical considerations in occipitocervical fusion. Japanese Journal of Neurosurgery. 2013;22(6):420-26.

29. Kuroki H, Rengachary SS, Goel VK, Holekamp SA, Pitkanen V, Ebraheim NA. Biomechanical comparison of two stabilization techniques of the atlantoaxial joints: transarticular screw fixation versus screw and rod fixation. Neurosurgery. 2005;56(1 Suppl):151-59; discussion -9.

30. Lapsiwala SB, Anderson PA, Oza A, Resnick DK. Biomechanical comparison of four $\mathrm{C} 1$ to $\mathrm{C} 2$ rigid fixative techniques: anterior transarticular, posterior transarticular, C1 to $\mathrm{C} 2$ pedicle, and C1 to C2 intralaminar screws. Neurosurgery. 2006;58(3):516-21; discussion -21

31. Finn MA, Fassett DR, McCall TD, Clark R, Dailey AT, Brodke DS. The cervical end of an occipitocervical fusion: a biomechanical evaluation of 3 constructs. Laboratory investigation. J Neurosurg Spine. 2008;9(3):296-300.

32. Geck MJ, Truumees E, Hawthorne D, Singh D, Stokes JK, Flynn A. Feasibility of rigid upper cervical instrumentation in children: tomographic analysis of children aged 2-6. Clinical Spine Surgery. 2014;27(3)

33. Paramore CG, Dickman CA, Sonntag VK. The anatomical suitability of the C1-2 complex for transarticular screw fixation. Journal of Neurosurgery. 1996;85(2):221-24.

34. Chern JJ, Chamoun RB, Whitehead WE, Curry DJ, Luerssen TG, Jea A. Computed tomography morphometric analysis for axial and subaxial translaminar screw placement in the pediatric cervical spine. J Neurosurg Pediatr. 2009;3(2):121-28.

35. Anderson RC, Kan P, Gluf WM, Brockmeyer DL. Long-term maintenance of cervical alignment after occipitocervical and atlantoaxial screw fixation in young children. $J$ Neurosurg. 2006;105(1 Suppl):55-61. 
36. Douglas L. Brockmeyer, Julie E. York, Ronald I. Apfelbaum Anatomical suitability of C1-2 transarticular screw placement in pediatric patients. Journal of Neurosurgery: Spine. 2000;92(1):7-11.

37. Mazur MD, Sivakumar W, Riva-Cambrin J, Jones J, Brockmeyer DL. Avoiding early complications and reoperation during occipitocervical fusion in pediatric patients. J Neurosurg Pediatr. 2014;14(5):465-75.

38. Wang J, Vokshoor A, Kim S, Elton S, Kosnik E, Bartkowski H. Pediatric atlantoaxial instability: management with screw fixation. Pediatr Neurosurg. 1999;30(2):70-78.

39. Lee SH, Kim ES, Sung JK, Park YM, Eoh W. Clinical and radiological comparison of treatment of atlantoaxial instability by posterior $\mathrm{C} 1-\mathrm{C} 2$ transarticular screw fixation or $\mathrm{C} 1$ lateral mass-C2 pedicle screw fixation. J Clin Neurosci. 2010;17(7):886-92.

40. Wu X, Li Y, Tan M, Yi P, Yang F, Tang X, et al. Long-term clinical and radiologic postoperative outcomes after $\mathrm{C} 1-\mathrm{C} 2$ pedicle screw techniques for pediatric atlantoaxial rotatory dislocation. World Neurosurgery. 2018;115:e404-e21.

41. Goel A, Kulkarni AG, Sharma P. Reduction of fixed atlantoaxial dislocation in 24 cases. Journal of Neurosurgery: Spine. 2005;2(4):505-509.

42. Li P, Bao D, Cheng H, Meng F, Li J. Progressive halo-vest traction preceding posterior occipitocervical instrumented fusion for irreducible atlantoaxial dislocation and basilar invagination. Clinical Neurology and Neurosurgery. 2017;162:41-46.

43. Meng Y, Chen H, Lou J, Rong X, Wang B, Deng Y, et al. Posterior distraction reduction and occipitocervical fixation for the treatment of basilar invagination and atlantoaxial dislocation. Clinical Neurology and Neurosurgery. 2016;140:60-67.

44. Gluf WM, Schmidt MH, Apfelbaum RI. Atlantoaxial transarticular screw fixation: a review of surgical indications, fusion rate, complications, and lessons learned in 191 adult patients. Journal of Neurosurgery: Spine. 2005;2(2):155-63.

45. Dunn R, Ombachi R. Transarticular screw fixation of the atlantoaxial spine: a safe and effective option. SA Orthopaedic Journal. 2006(August).

46. Gluf WM, Brockmeyer DL. Atlantoaxial transarticular screw fixation: a review of surgical indications, fusion rate, complications and lessons learned in 67 pediatric patients. Journal of Neurosurgery: Spine. 2005;2(2):164-69.

47. Brockmeyer DL, Apfelbaum RI. A new occipitocervical fusion construct in pediatric patients with occipitocervical instability. Journal of Neurosurgery: Spine. 1999;90(2):271-75.

48. Brockmeyer DL, York JE, Apfelbaum RI. Anatomical suitability of C1-2 transarticular screw placement in pediatric patients. Journal of Neurosurgery: Spine. 2000;92(1):7-11.

49. Elliott RE, Tanweer O, Boah A, Morsi A, Ma T, Smith ML, et al. Atlantoaxial fusion with screw-rod constructs: meta-analysis and review of literature. World Neurosurgery. 2014;81(2):411-21.

50. Zhang Y-H, Shen L, Shao J, Chou D, Song J, Zhang J. Structural allograft versus autograft for instrumented atlantoaxial fusions in pediatric patients: radiologic and clinical outcomes in series of 32 patients. World Neurosurgery. 2017;105:549-56.

51. Kosnik-Infinger L, Glazier SS, Frankel BM. Occipital condyle to cervical spine fixation in the pediatric population. J Neurosurg Pediatr. 2014;13(1):45-53.

52. Goel A, Desai KI, Muzumdar DP. Atlantoaxial fixation using plate and screw method: a report of 160 treated patients. Neurosurgery. 2002;51(6):1351-57.

53. Harms J, Melcher RP. Posterior C1-C2 Fusion with polyaxial screw and rod fixation. Spine. 2001;26(22):2467-71.

54. Chamoun RB, Relyea KM, Johnson KK, Whitehead WE, Curry DJ, Luerssen TG, et al. Use of axial and subaxial translaminar screw fixation in the management of upper cervical spinal instability in a series of 7 children. Neurosurgery. 2009;64(4):734-39.

55. Haque A, Price AV, Sklar FH, Swift DM, Weprin BE, Sacco DJ. Screw fixation of the upper cervical spine in the pediatric population. Clinical article. J Neurosurg Pediatr. 2009;3(6):529-33.

56. Leonard JR, Wright NM. Pediatric atlantoaxial fixation with bilateral, crossing C-2 translaminar screws. Journal of Neurosurgery: Pediatrics. 2006;104(1):59-63.

57. Dunn R, Stander H. Atlanto-axial fusion: Magerl transarticular versus Harms instrumentation techniques. SA Orthopaedic Journal. 2014;13(2):31-34.
58. Huang D-G, Zhang X-L, Hao D-J, Yu C-C, Mi B-B, Yuan Q-L, et al. Posterior atlantoaxial fusion with a screw-rod system: Allograft versus iliac crest autograft. Clinical Neurology and Neurosurgery. 2017;162:95-100.

59. Iyer RR, Tuite GF, Meoded A, Carey CC, Rodriguez LF. A modified technique for occipitocervical fusion using compressed iliac crest allograft results in a high rate of fusion in the pediatric population. World Neurosurgery. 2017;107:342-50. 